\title{
Posterior patterning by the Caenorhabditis elegans even-skipped homolog vab-7
}

\author{
Julie Ahringer ${ }^{1}$ \\ Medical Research Council Laboratory of Molecular Biology, Cambridge CB2 2QH, UK
}

\begin{abstract}
Patterning of the posterior end in animals is not well understood. Homologs of Drosophila even-skipped (eve) have a similar posterior expression pattern in many animals, and in vertebrates they are linked physically to the "posterior" ends of homeotic clusters (HOM-C), suggesting a conserved role in posterior development. However, the function of this posterior expression is not known. Here I show that the Caenorhabditis elegans gene vab-7 encodes an eve homolog that is required for posterior development and expressed in a pattern strikingly similar to that of vertebrate eve genes. Using a four-dimensional recording system, I found that posterior body muscles and the posterior epidermis are patterned abnormally in vab-7 mutants, but commitment to muscle and epidermal fates is normal. Furthermore, vab-7 activity is required for the complete expression of the most posterior HOM-C gene egl-5 in muscle cells, supporting the idea that eve homologs may act with the HOM-C to determine posterior cell fates. The conservation of sequence and expression pattern between vab-7 and eve homologs in other animals argues that most $e v e$ genes have posterior mesodermal and ectodermal patterning functions.
\end{abstract}

[Key Words: C. elegans; pattern formation; lineage analysis; HOX genes]

Received January 31, 1996; revised version accepted March 21, 1996.

During development, maternal (and paternal) products are important for setting up early asymmetries in the embryo (Slack 1991). Later, in most if not all animals, an evolutionarily conserved cluster of homeotic genes (the HOM-C) helps pattern the central body along the anterior-posterior $\{a / p)$ axis (for review, see McGinnis and Krumlauf 1992; Kenyon 1994). How the extremities are patterned is still largely mysterious.

One conserved gene suggested to have a role in posterior patterning is even-skipped (eve). This is based on its posterior expression in many organisms and its physical linkage to the "posterior" ends of vertebrate HOX clusters (Ruiz i Altaba and Melton 1989a,b; Bastian and Gruss 1990; D’Esposito et al. 1991; Faiella et al. 1991; Bastian et al. 1992; Dush and Martin 1992; Patel et al. 1992; Joly et al. 1993; Dollé et al. 1994). In most animals, eve genes have three major phases of expression: $(1)$ in the developing posterior mesoderm and ectoderm, (2) in developing posterior structures such as the tail bud in mouse, and $|3|$ in the developing nervous system |the segmental expression of Drosophila eve (Macdonald et al. 1986; Frasch et al. 1987) is unusual]. The shared posterior expression pattern suggests that these genes have a conserved function in posterior development, but neither the function of this expression nor any functional

\footnotetext{
${ }^{1}$ Present address: University of Cambridge, Department of Genetics,
} Downing Street, Cambridge CB2 3EH, UK. interaction with the posterior part of the HOX cluster has yet been reported.

Caenorhabditis elegans also has a homeotic cluster that has been shown to be important for establishing cell fates along the $a / p$ axis (for review, see Salser and Kenyon 1994l. The functions of these genes have been studied mainly during postembryonic development. Zygotic patterning in the embryo has been largely ignored because of difficulties in analysis. In particular, it was not possible to routinely follow cell lineages in mutant embryos because of the number of simultaneous cell divisions to be watched. This problem has been overcome by the devalopment of a "four-dimensional" (4D) video recording sy stem that can be used to look for alterations in the divisions, migrations, and differentiation of almost any cell in the embryo (Hird and White 1993). As the embryonic cell lineage is essentially invariant in $C$. elegans (Sulston et al. 1983), this type of data is a good measure of pattern alteration, and is especially useful where defects may not be obvious or interpretable from looking at a differentiated embryo.

Here, I show that the C. elegans gene vab-7 encodes an eve homolog. Using the 4D recording system, I found that $v a b-7$ functions in posterior muscle and epidermal patterning in the embryo. In addition, posterior muscle cells require vab-7 activity for complete expression of the most posterior HOM-C gene egl-5. Because the posterior expression of vab-7 is similar to that of eve in other organisms, it is likely that eve genes have posterior patterning functions in most animals. 


\section{Results}

vab-7 encodes an eve homolog

A sequence highly similar to the eve homeo box of Drosophila was identified by the $C$. elegans sequencing consortium during the partial sequencing of yeast artificial chromosome (YAC) Y52D3. Figure 1A shows an alignment of this sequence with eve homologs from other organisms. The $C$. elegans sequence has $\geqslant 80 \%$ amino acid identity with any other eve homeo domain; the closest non-eve homeo domain is from Drosophila rough (Tomlinson et al. 1988), with $59 \%$ identity.

I searched the genetic map in the region of $\mathrm{Y} 52 \mathrm{D} 3$ for a previously identified gene that could correspond to this sequence. Mutations in the gene vab-7 (for variable $a b$ normal) result in posterior defects (J. Culotti, pers. comm.), which made it a good candidate. Two experiments showed that $v a b-7$ does encode the eve homolog. First, DNAs containing the eve gene rescue the vab-7 mutant phenotype (Fig. 1B). Second, two alleles of $v a b-7$ (e1562 and ed7) each carry a mutation in the homeo domain (arrows in Fig. 1A, circled in Fig. 1C). The $e 1562$ mutation introduces a stop codon in the fifth amino acid of the homeo domain. This truncation should remove about two-thirds of the protein, including most of the homeo domain, and is predicted to cause a strong reduction of $v a b-7$ function, consistent with the results of genetic experiments (see Materials and methods). The ed7 mutation changes an arginine to a cysteine near the end of the recognition helix, in a residue that makes a phosphate contact in the Antp (C39S) homeo domainDNA complex (Billeter et al. 1993; see Gehring et al. 1994 for a review of homeo domain structure). This same arginine residue is changed to a histidine by the temperature-sensitive ID 19 mutation in Drosophila eve (Frasch et al. 1988). The vab-7(ed7) mutation is not temperature sensitive and probably retains partial activity (see belowl.

To identify more of the vab-7 coding region, I isolated and sequenced a cDNA clone (Fig. 1C). This cDNA is
A
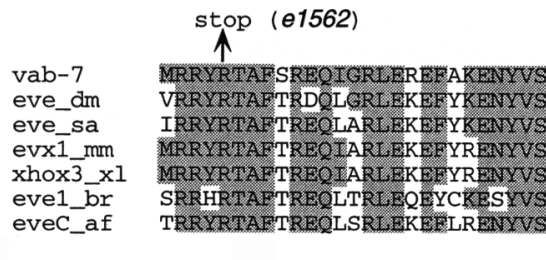

B

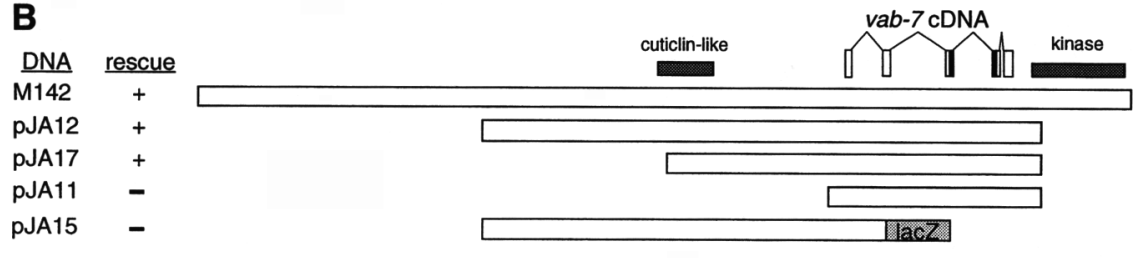

C

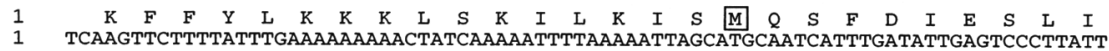
$\begin{array}{lllllllllllllllllllllllllllllll}27 & \text { G } & \text { V } & \text { N } & \text { K } & \text { V } & \text { P } & \text { S } & \text { L } & \text { V } & \text { E } & \text { M } & \text { V } & \text { A } & \text { A } & \text { S } & \text { R } & \text { A } & \text { S } & \text { S } & F & \text { S } & \text { P } & P & F & E & Q & Q\end{array}$ 81 GGGGTTAATAAGGTCCCATCACTTGTGGAGATGGTCGCCGCATCTCGAGCTTCCTCATTTTCCCCTCCATTTGAGCAGCA $\begin{array}{lllllllllllllllllllllllllllll}53 & \text { H } & \text { H } & \text { D } & \text { P } & \text { M } & \text { G } & \text { V } & \text { V } & \text { A } & \text { A } & \text { A } & \text { A } & \text { A } & \text { A } & \text { A } & \text { A } & \text { A } & \text { G } & \text { R } & \text { H } & \text { H } & \text { P } & \text { Y } & \text { D } & N & R\end{array}$ 161 GCATCATGACCCGATGGTGTGGTGGCCGCAGCGGCAGCAGCAGCAGCCGCCGGACGTCATCATCCGTATGATAACCGAG

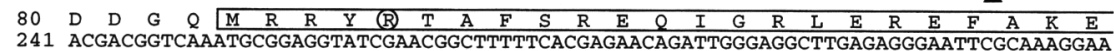

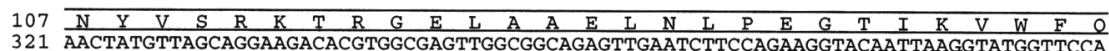

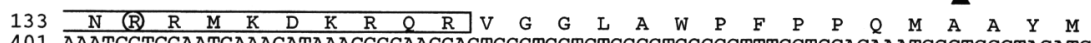
401 AAATCGTCGAATGAAAGATAAACGGCAACGAGTCGGTGGTCTCGCGTGGCCCTTTCCTCCACAAATGGCTGCCTACATGT

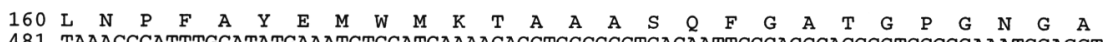
481 TAAACCCATTTGCATATGAAATGTGGATGAAAACAGCTGCCGCCTCACAATTCGGAGCCACGGGTCCCGGAAATGGAGCT $\begin{array}{lllllllllllllllllllllllllllll}187 & \text { Y } & G & N & N & G & S & S & T & S & P & S & A & A & G & S & \text { L } & P & F & \text { L } & P & P & \text { L } & G & \text { F } & P & S & F\end{array}$ 561 TATGGGAATAATGGATCAAGCACATCTCCATCAGCAGCTGGATCTCTTCCATTCCTTCCACCATTAGGTTTTCCATCATT $\begin{array}{lllllllllllllllllllllllllllll}213 & \text { L } & S & Q & N & S & T & K & S & P & S & S & P & H & S & D & D & S & S & K & S & K & N & T & S & S & D\end{array}$ 641 TTTATCACAAAATTCAACAAAATCTCCATCTTCTCCACATTCAGACGATTCCTCAAAATCGAAGAATACCTCAAGTGATG $\begin{array}{lllllllllllllllllllllllllllll}240 & \mathrm{D} & \mathrm{D} & \mathrm{E} & \mathrm{S} & \mathrm{K} & \mathrm{P} & \mathrm{V} & \mathrm{N} & \mathrm{F} & \mathrm{S} & \mathrm{N} & \mathrm{S} & \mathrm{P} & \mathrm{S} & \mathrm{S} & \mathrm{S} & \mathrm{S} & \mathrm{P} & \mathrm{S} & \mathrm{P} & \mathrm{Y} & \mathrm{S} & \mathrm{T} & \mathrm{D} & \text { * } & 263\end{array}$ 721 ATGATGAATCAAAACCTGTAAATTTTTCAAATAGCCCTTCCTCAAGTTCTCCCTCGCCTTATTCTACAGATTAATTCACT 801 ATTTTTTGGAAAAAAAATCGGCAAAAAAAAAAAAA 837
Figure 1. $v a b-7$ sequence and genomic structure. $|A|$ Alignment of the vab-7 homeo domain with those from other eve homologs. Residues identical with the vab-7 sequence are shaded. (eve dm) Drosophila eve (Macdonald et al. 1986; Frasch et al. 1987); (eve sal Schistocerca eve (Patel et al. 1992); (evx1 mm) Mus musculus evx1 (Bastian and Gruss 1990; Dush and Martin 1992); (xhox3 xl) Xenopus laevis Xhox3 (Ruiz i Altaba and Melton 1989a); (eveC_af) Acropora formosa (a coral) eveC (Miles and Miller 1992). (B) vab-7 genomic region and rescuing DNAs. Ml42 is a cosmid; pJAll, pJA12, and pAJ17 are genomic clones derived from M142. pIA15 is a vab-7::lacZ translational fusion. DNAs are represented by open rectangles indicating approximate region of overlap. $1+1$ The DNA has vab-7 rescuing activity; $\mid-1$ The DNA has no rescuing activity. Shaded boxes above the open boxes indicate the regions of adjacent genes predicted by the GENEFINDER program (P. Green, pers. comm.). Boxes connected by lines represent exons of the vab-7 cDNA (sequence shown in $C$ ); the homeo domain is indicated in black. $(C)$ Sequence of a partial vab-7 cDNA. The open reading frame is shown in one-letter code above the nucleotide sequence; a possible start methionine is boxed at amino acid 17. A polyalanine stretch is underlined, the homeo domain is boxed, and solid triangles mark the locations of introns. Amino acids changed by $v a b-7$ mutations are circled: vab-7(e1562) is a $\mathrm{C} \rightarrow \mathrm{T}$ change at nucleotide 264 (codon change $\mathrm{CGA} \rightarrow$ TGA, $\mathrm{R}$ (amino acid 88 ) to Stopl. vab-7(ed7) is a $\mathrm{C} \rightarrow \mathrm{T}$ change at nucleotide 405 [codon change CGT $\rightarrow$ GTG, R (amino acid 134 ) to $\mathrm{Cl}$. 


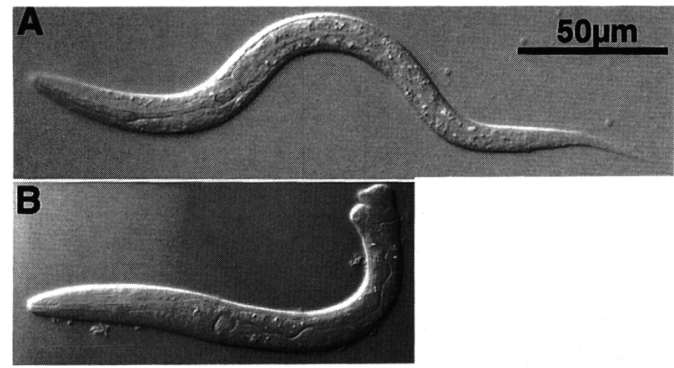

Figure 2. $v a b-7$ phenotype. (A) Wild-type first-stage (L1) larvae. (B) vab-7(e1562) mutant $\mathrm{L} 1$ larvae. The vab-7 mutant larva has a severely disorganized posterior end and uncoordinated movement. Anterior, left.

$880 \mathrm{bp}$ long and has one long open reading frame, beginning at the $5^{\prime}$ end of the clone and ending with a stop codon at position 700 . Therefore, it appears to encode the carboxy-terminal end of the protein. Using the GENEFINDER program (P. Green, pers. comm.), no additional 5 ' exons could be predicted in the genomic sequence; however, an in-frame methionine that could be the start of the protein is found at position 17 (boxed in Fig. 1C). The cDNA ends with a run of A residues, most of which are found in the genomic sequence, suggesting that this is not the true $3^{\prime}$ end of the transcript. There is no obvious polyadenylation signal in the clone, but one that might be used is located $400 \mathrm{bp}$ further downstream in the genomic sequence. From Northern blotting, $v a b-7$ RNA is estimated to be $1.4 \mathrm{~kb}$ (Fig. 3A, below), therefore this cDNA clone is missing $\sim 500$ nucleotides.

Besides the homeo box, the amino acid sequence shows two additional features in common with other eve homologs: a polyalanine stretch (underlined in Fig. 1C) and a region rich in serine and proline residues at the carboxyl terminus of VAB-7; Fig. 1C).

\section{vab-7 mutants have posterior defects}

Figure 2 shows the phenotype caused by the strong $v a b-7$ allele $e 1562$. Mutants have a severely disorganized posterior region and uncoordinated movement. Despite these defects, most $(85 \%)$ vab-7(e1562) animals are viable. The lethality may result from the inability to defecate, as the intestines of dead larvae are extremely bloated. Two other alleles of vab-7 have weaker effects. vab-7(ed7) mutants have a similar movement defect, but a slightly less disorganized posterior region than $v a b$. 7(e1562); vab-7(ed6) mutants have nearly wild-type movement, but have a bobbed tail.

The vab-7 movement defect shows an interesting feature. When wild-type animals are touched on the head (or tail), they move backward (or forward), propelling themselves by the alternate contraction and relaxation of dorsal and ventral body wall muscles. When vab7(e1562) mutants back up in response to head touch, they flex both dorsally and ventrally, although more slowly and less smoothly than wild type. However, when vab-7(e1562) mutants move forward in response to tail touch, they curl ventrally and become locked in this position for several seconds. This difference in behavior when moving forward versus backing suggests that at least part of the vab-7 movement defect has a neuronal origin, as the same muscles are used for movement in both directions; as yet, it is not known which neurons might be affected.

\section{Dorsal posterior muscle and epidermal precursors express vab-7 RNA}

$v a b-7$ RNA is expressed primarily in embryos, $\mathrm{L} 1$ and $\mathrm{L} 2$ larvae (Fig. 3A). To see where in the embryo vab-7 is expressed, RNA in situ hybridization was done. vab-7 RNA is first detected at the 100-cell stage, in four cells at the posterior end (Cxxp cells; Fig. 3B-D). These four cells are descendants of the $\mathrm{C}$ blastomere (one of six so-called founder cells), and give rise to primarily dorsal posterior body wall muscles (hereafter "muscle" will be used to mean body wall muscle) and epidermis (also called the hypodermis in C. elegans), as well as two neurons (Fig. 3Dl. vab-7 RNA is also detected in daughters of these cells; however, in situ hybridization staining of older embryos was variable (not shown), possibly because the level of expression is reduced.

To look more easily at $v a b-7$ expression, I made a translational fusion with $l a c Z$ (see Fig. 1B, pIA15). Early
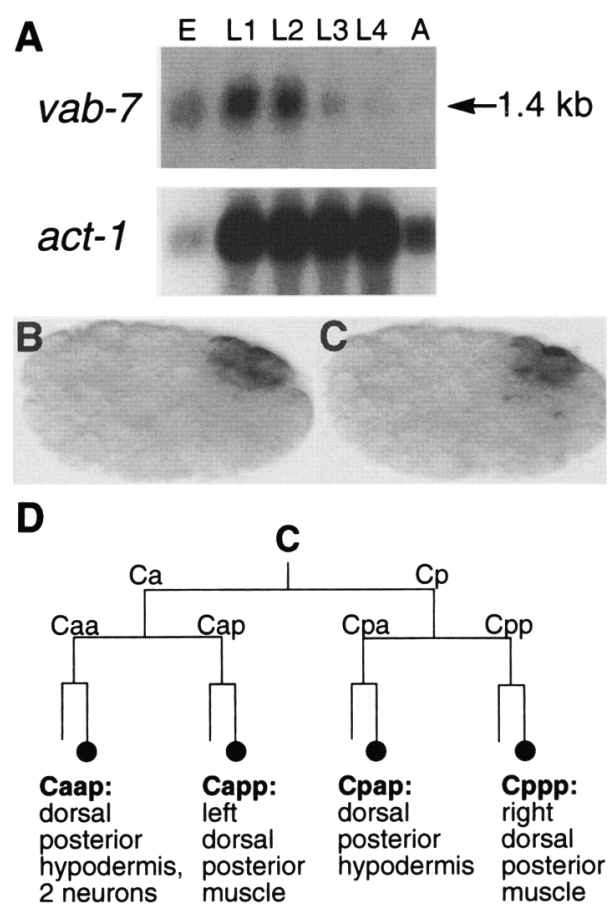

Figure 3. $v a b-7$ expression. $(A)$ Developmental Northern blot with RNA from E (embryos), Ll to L4 larvae, and A (adults). (Top) vab-7 probe; (bottom) act-1 probe as a loading control. (B.C) Earliest $v a b-7$ RNA detected by in situ hybridization. Shown are two focal planes of a 100-cell stage embryo with four positive cells, two in $B$ and two in $C$. $(D)$ Partial lineage of the $\mathrm{C}$ blastomere. Cells are named by adding " $\mathrm{a}$ " to an anterior daughter and " $\mathrm{p}$ " to a posterior daughter; horizontal lines show cell divisions, vertical lines indicate time. $(\mathbf{C})$ Cells positive in $B$ and $C$; below are their names and the cell types they produce. 

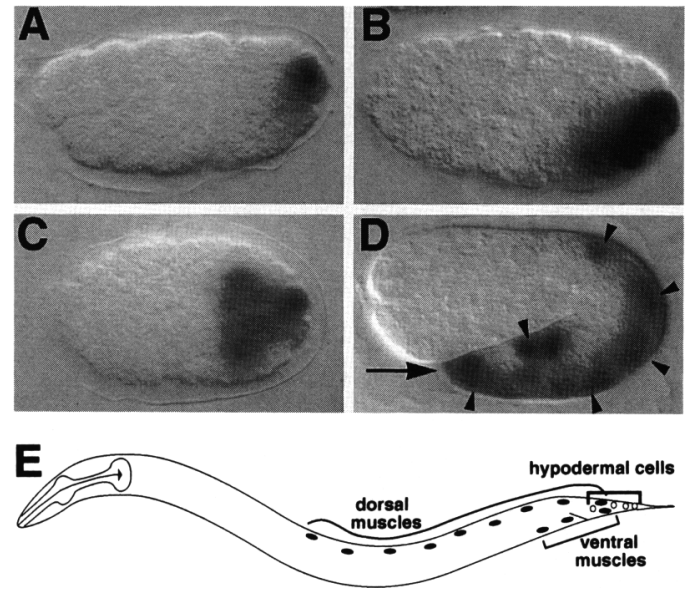

Figure 4. $v a b-7:: l a c Z$ expression. $(A-D)$ Embryos containing an $e I s 24$, an integrated $v a b-7:: 1 a c Z$ fusion gene (plasmid pIA 15 in Fig. (B), stained for $\beta$-galactosidase activity using X-gal. Anterior, left. $(A) 100$-cell stage; $(B) \sim 200$ cells; $(C) \sim 400$ cells. $|D|$ Embryo during early morphogenesis 1.5 -fold stage. Arrowheads point to stained muscle cells; the majority are dorsal, located at the periphery. The arrow points to hypodermal cell staining at the posterior. No staining is detectable after the early L1 stage. Because vab-7 RNA is expressed in L2 larvae (Fig. 3A), the vab. $7:: 1 a c Z$ construct may lack some regulatory elements. $|E|$ Cartoon showing cells that express $v a b-7:: 1 a c Z$ near the end of morphogenesis. Most cells that stain are descended from the $\mathrm{C}$ blastomere: nine dorsal and three ventral muscles on each side as well as some dorsal hypodermal cells (e.g., Cpapaa and Cpapap|. In addition, two hypodermal cells produced by the $A B$ blastomere that form the hypl0 syncytium also express the fusion gene.

expression of $v a b-7:: 1 a c Z$ is identical to that seen by in situ hybridization, in the 4 Cxxp cells (Fig. 4A). Descendants of these cells as well as additional C-derived posterior muscle cells stain as development proceeds (Fig. $4 \mathrm{~B}, \mathrm{C}$ ). At the time of embryonic elongation, all nine posterior dorsal muscles and the three most posterior ventral muscles descended from the $\mathrm{C}$ blastomere express vab-7::1acZ (Fig. 4D,E). At this time, staining is also detected in the two most posterior epidermal cells, which form the hypl0 syncytium (Fig. 4D,E). These two cells are descended from the $\mathrm{AB}$ founder cell and therefore are not related lineally to the other expressing cells, but are also located in the posterior region. To summarize, $v a b$. $7:: l a c Z$ is expressed in dorsal posterior epidermal cells, in posterior muscles (with more expression dorsally than ventrally), and in the precursors of two neurons (Fig. 4E). This pattern is strikingly similar to that seen for eve in other organisms, where expression is commonly in posterior mesodermal (and usually also ectodermal) tissues, and in the developing nervous system. Furthermore, regional expression in unrelated cells as opposed to strict lineal expression suggests a general role in posterior patterning.

\section{Pattern defects in the posterior hypodermis}

The posterior hypodermis of vab-7 mutants is lumpy and disorganized. To investigate how the hypodermis might be abnormally patterned, I examined the development of hypodermal cells descended from the $\mathrm{C}$ blastomere in vab-7 mutants. A 4D video system (Hird and White 19931 was used to record embryonic development in multiple focal planes and then analyze the divisions and migrations of individual cells. In all cases, hypodermal lineages had the normal number of divisions and cells appeared to develop as hypodermal cells based on cell morphology and their surface positions. However, at least two cells, which are descendants of the vab-7-expressing cell Cpap, have characteristics of more anterior hypodermal cells. In wild-type animals, the daughters of Cpap divide 10 min later than the daughters of the more anterior precursor Cpaa (Fig. 5A). In vab-7 mutants, one daughter of Cpap (Cpapa) divides $10 \mathrm{~min}$ early, at the same time as the Cpaa daughters (shaded in Fig. 5A). This suggests that the Cpapa cell may have taken on a fate like its more anterior cousins.

To further investigate the Cpapa fate, the positions of its daughters were followed. In the wild-type, most dorsal hypodermal cells are born in two rows on the dorsal

A
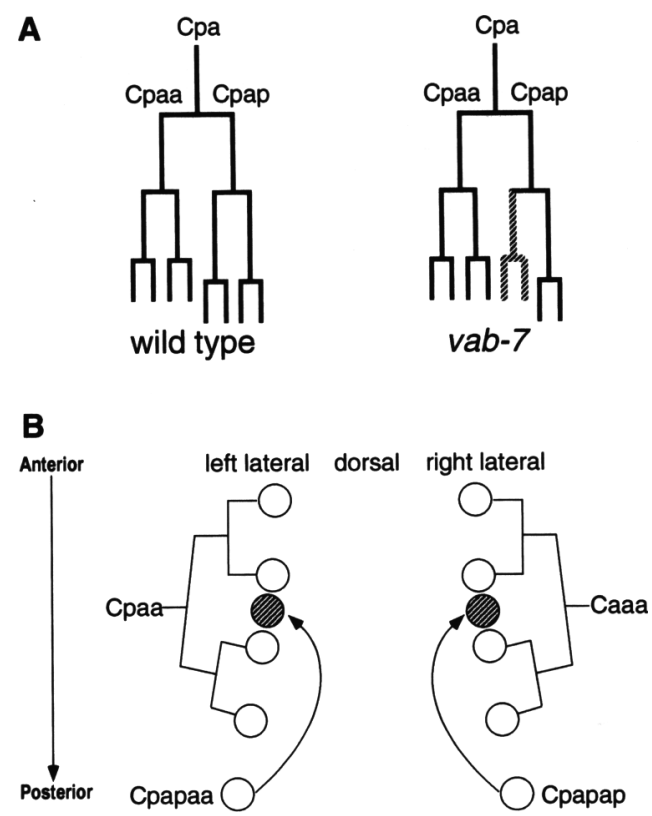

Figure 5. Hypodermal defects in vab-7(e1562) mutants. $(A \mid$ Wild-type and vab-7 mutant Cpa cell lineages. In the wild type, the two daughters of Cpap divide 10 min later than the daughters of Cpaa. In vab-7 mutants, Cpapa, the anterior daughter of Cpap (shown by shaded lines), divides $10 \mathrm{~min}$ early, at the same time as the daughters of Cpaa. Cells are named by adding " $\mathrm{a}$ " to an anterior daughter and " $\mathrm{p}$ " to a posterior daughter; horizontal lines show cell divisions, vertical lines indicate time. $|B|$ Schematic diagram showing the relative positions of some posterior hypodermal nuclei. Open circles show wild-type positions; shaded circles show vab-7 mutant positions. (Top) Anterior; (bottom) posterior. In vab-7 mutants, the daughters of Cpapa (Cpapaa and Cpapap/ lie anterior to their normal locations. The positions shown were seen in two individuals. In a third animal, both Cpapaa and Cpapap were on the left-hand side, at the position indicated here for Cpapaa. 
surface (Sulston et al. 1983). These nuclei then migrate in between each other across the dorsal midline to the opposite side, and eventually stop at left and right lateral positions. In these rows, the Cpapa daughters lie just posterior to the granddaughters of Cpaa and Caaa (final wild-type positions are shown by open circles in Fig. 5B|. In vab-7 mutants, the Cpapa daughters (Cpapaa and Cpapap) are located anterior to their normal positions (filled circles in Fig. 5B). Most often, they first migrate anteriorly to the Caaa and Cpaa daughters, and then interdigitate along with them. Therefore, by two criteria, the early cell division time and the anterior location of its daughters, the posterior Cpapa hypodermal cell appears to be transformed into a more anterior hypodermal cell. Other posterior hypodermal cells are also sometimes abnormally positioned (not shown). The malformed posterior region of vab-7 mutants is likely to result at least partially from incorrect hypodermal cell locations, but affected cells may also produce the wrong type of hypodermal tissue.

\section{Posterior muscles in vab-7 mutants are disorganized}

As an initial assay of proper muscle patterning, I looked at overall muscle organization using two markers that stain muscle cells (Fig. 6). Muscles in C. elegans are mononucleate and are arranged in four rows along the animal. On each side, one row is dorsal and one is ventral (Fig. 7A). During embryogenesis, muscle precursor cells are first separated into right and left sides, and then muscles split into dorsal and ventral rows during early morphogenesis (one dorsal and one ventral row can be seen in Fig. 6A). In vab-7 mutant embryos, there is no clear separation of dorsal and ventral rows in the posterior. Muscles are often bunched together laterally (Fig. 6B, thick arrow), and strings of muscle material connect dorsal and ventral muscles (Fig. 6B, thin arrow). In adults, muscles are often stranded in lateral positions, attaching to both rows (Fig. 6D), and misplaced muscles form rings with neighboring rows (Fig. 6E). These data show that dorsal and ventral muscle rows do not form properly in the posterior, and suggest that vab-7 is important for dorsal-ventral muscle patterning.

\section{Dorsal-ventral and anterior-posterior muscle patterning defects in vab-7 mutants}

From looking at fixed animals, it is not possible to determine which muscles are mispositioned. There are no defining characteristics to recognize different muscles in C. elegans; however, each muscle cell is descended from a known series of cell divisions and occupies a particular position with defined neighbors in a wild-type animal (see Fig. 7A). Dorsal-ventral (d/v) muscle patterning involves the allocation of cells to dorsal versus ventral muscle rows and the subsequent separation of these rows. Along the $\mathrm{a} / \mathrm{p}$ axis, muscles are found in a defined order (Fig. 7A); deviation from this sequence is an indication of abnormal a/p patterning. I used these features

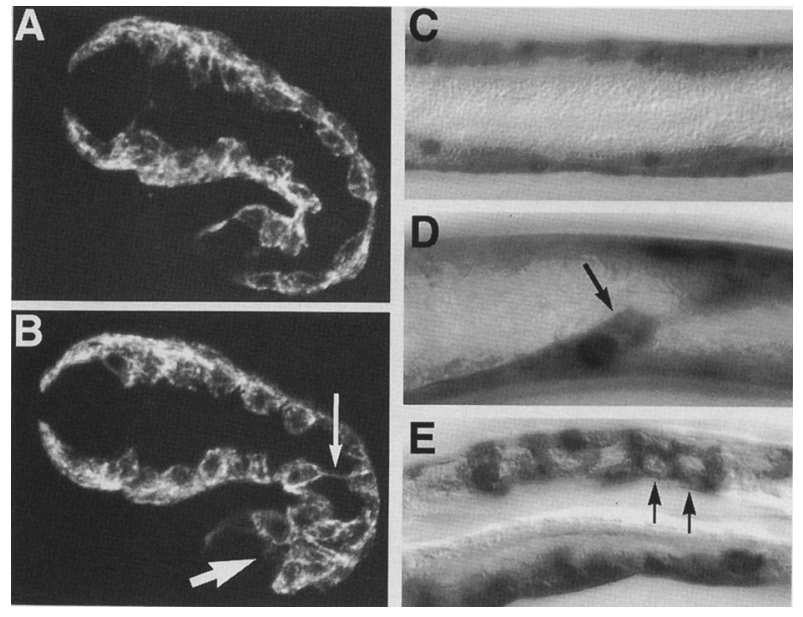

Figure 6. Posterior muscle disorganization in vab-7 mutants. $(A, B)$ Left views of 1.5 -fold embryos stained with $\mathrm{mAb} \mathrm{NE2/}$ 4 C6.3, which shows the outlines of muscle cells $\mid$ Goh and Bogaert 1991l. In each, one dorsal row and one ventral row are visible. Dorsal, up. $|A|$ Wild type. $|B|$ vab-7 mutant; the thick arrow points to the posterior region where dorsal and ventral muscles are jumbled and touch each other laterally. The thin arrow points to a strand of muscle material that connects dorsal and ventral muscle rows. $(C-E)$ Adults expressing PD56 (cc56), a body wall myosin reporter gene (unc-54::lacZ; Okkema et al. 1993) stained with X-gal. In each panel, one dorsal row $(t o p)$ and one ventral row (bottom) is visible. $(C)$ Wild type. (D) vab-7 mutant; the arrow shows a muscle cell connected to both dorsal and ventral muscle rows. (E) vab-7 mutant; arrows show several misplaced muscles near a dorsal row that form rings of muscle.

to analyze muscle patterning in $v a b-7$ mutants. Using the $4 \mathrm{D}$ recording system, cells were followed until the bean stage, when the $\mathrm{C}$ muscle cell divisions are complete and $\sim 1 \mathrm{hr}$ before muscle contractions begin.

Figure $7 \mathrm{~A}$ diagrams the 81 muscles in a newly hatched L1 larvac; those descended from the $\mathrm{C}$ blastomere are colored. vab-7 is expressed in a subset of these: All dorsal and some ventral muscles (red, orange, and yellow cells, bold numbers), but not more anterior ventral ones (purple cells, outlined numbers).

Muscle positions in $v a b-7$ mutants indicate that muscles are mispatterned along the $\mathrm{d} / \mathrm{v}$ axis. In contrast to wild type, neat dorsal and ventral rows are not formed (Fig. 7B). Dorsal and ventral muscle cells are closely opposed and often touch each other, and muscle cells are found in aberrant positions along the $\mathrm{d} / \mathrm{v}$ axis. Furthermore, patterning along the $\mathrm{a} / \mathrm{p}$ axis is also defective; some dorsal muscle cells are in the wrong a/p order (see, e.g., orange rows in Fig. 7B). Overall, dorsal muscles are more disorganized than ventral ones, with those expressing $v a b-7$ being most affected. Taken together, these results indicate that $v a b-7$ is required for both $\mathrm{d} / \mathrm{v}$ and $\mathrm{a} / \mathrm{p}$ muscle patterning in the posterior region, but not for the specification of cells as muscle.

The cell division pattern of the $\mathrm{C}$ muscle lineages in $v a b-7$ mutants are similar to those in wild-type embryos except that two ventral right muscle precursors always fail to divide the final time /Cppaaa and Cppaap, mothers 
A

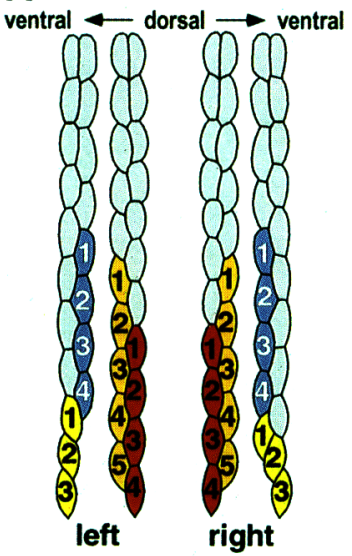

B

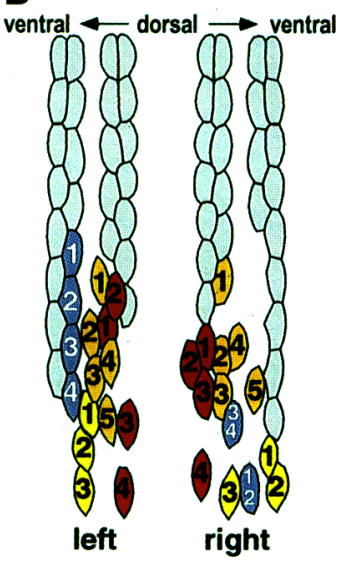

C

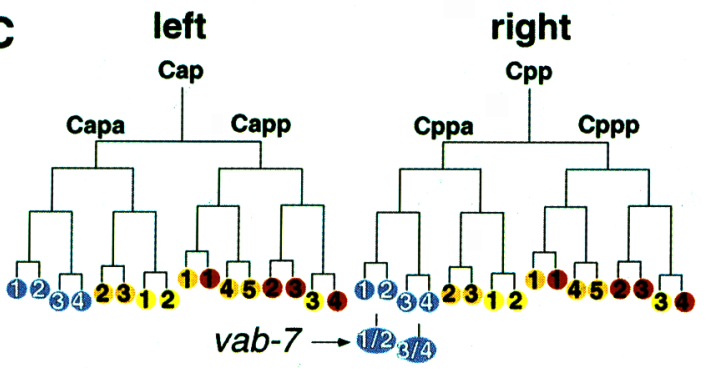

Figure 7. Muscle patterning defects in vab-7 mutants. $|A|$ Schematic diagram showing wild-type organization of the 81 muscle cells present at hatching (based on Fig. 15 in Sulston et al. 19831. Muscles are arranged in four rows that run from anterior to posterior along the animal. Muscle cells produced by the $\mathrm{C}$ blastomere are colored; those produced from other blastomeres are shaded gray. Boldface numbers indicate muscle cells that express vab-7 (red, orange, and yellow); outlined numbers show muscle cells that do not express vab-7 (purplel. Numbers are assigned arbitrarily to facilitate comparison of wildtype and vab-7 mutant muscle cell positions. $|B|$ Muscle cell positions in one vab-7(e1562) mutant. Muscle cell divisions and positions were followed in four individuals to the bean stage; this shows a representative example. Refer to the text for a description of defects. $(C) \mathrm{C}$ blastomere muscle cell lineages. Colors and numbers correspond to those in $A$ and B. vab-7 mutant lineages are similar to that shown except that Cppaaa and Cppaap do not divide the final time /shown as purple cells labeled $1 / 2$ and $3 / 4$ on the right sidel and Cppppp (which gives rise to the posterior-most cell of the dorsal and ventral righthand rows / divides -25 min early.

of right-hand purple muscles $1 / 2$ and $3 / 4$; Fig. $7 \mathrm{~B}, \mathrm{Cl}$. These cells do not express $v a b-7$, suggesting a possible nonautonomous effect. These cells do, however, appear to be muscle cells based on their morphology and positions. Lineages of non-C muscle cells (gray in Fig. 7) that adjoin the $\mathrm{C}$ muscles were followed in a few individuals. In general these are in wild-type positions (not shown), suggesting that vab-7 activity is required only for organization of muscles made by the $\mathrm{C}$ blastomere.

Reduced egl-5 muscle cell expression in vab-7 mutants

The regional expression of $v a b-7$ overlaps that from two genes in the homeotic cluster mab-5 and egl-5 (this study; Costa et al. 1988; Cowing and Kenyon 1992; Wang et al. 1993). To ask whether vab-7 might regulate the expression of either gene, I compared the expression of $m a b-5$ and $e g 1-5$ reporter genes in wild-type and vab-7 mutant embryos. I found no change in the total number of cells that express mab-5::lac $Z$ in $v a b-7$ mutants compared to wild-type; however, about six fewer cells express egl-5::lacZ (see Materials and methods). Because $v a b-7$ and $e g l-5$ are coexpressed in the three most posterior muscle cells in each quadrant (Fig. 8A), I asked whether muscle cells fail to express egl-5::lacZ in $v a b-7$ mutants by counting the number of cells costained with antibodies to muscle and $\beta$-galactosidase. Significantly fewer muscle cells express egl-5::lacZ in vab-7 mutants compared to wild type (Fig. $8 \mathrm{~B}$; on average 6.8 cells in vab-7 mutants versus 11.3 cells in wild type). Furthermore, in those muscle cells where egl-5::lacZ expression is detectable, staining is generally much weaker than in wild-type embryos (cf. egl-5 muscle staining with other eg 1.5 positive cells in Fig. $8 \mathrm{C}$ with D). These results suggest that posterior muscle cells require $v a b-7$ activity for egl-5 expression, raising the possibility that $v a b-7$ is a positive regulator of egl-5. Because egl-5 muscle expression is not completely abolished in $v a b-7$ mutants, either this allele [vab-7(e1562)] does not completely remove all vab-7 activity, or vab-7 is important, but not essential for egl-5 expression. The loss of egl-5 activity cannot account for the posterior muscle disorganization in vab-7 mutants, as overall muscle organization is normal in egl-5 mutant embryos (Fig. 8E). However, defects in a/p patterning would probably not be seen by this type of general muscle staining.

\section{Discussion}

The vab-7 gene of $C$. elegans encodes an eve homolog expressed in developing posterior muscle and epidermis. $v a b-7$ activity is required for posterior patterning of these tissues, but not for commitment to epidermal or muscle cell fates. In the development of posterior body muscle, vab-7 is necessary for $\mathrm{d} / \mathrm{v}$ and a/p patterning. In addition, some posterior epidermal cells require $v a b-7$ activity to have posterior rather than anterior fates. This is the first demonstration that an eve homolog has a posterior patterning function. Because the expression pattern of $v a b-7$ is similar to that of eve homologs in other animals, this suggests that most eve genes also have $\mathrm{a} / \mathrm{p}$ and $\mathrm{d} / \mathrm{v}$ patterning roles. Below, I discuss the functions of $v a b-7$ and the relationship between $v a b-7$ and other patterning genes.

\section{eve genes in other organisms}

eve homologs have been identified in many animals, ranging from coral to human (Ruiz i Altaba and Melton 1989a; Bastian and Gruss 1990; D'Esposito et al. 1991; Faiella et al. 1991; Dush and Martin 1992; Miles and Miller 1992; Patel et al. 1992; Joly et al. 19931. These genes all have a highly conserved homeo domain, therefore they are thought to function as transcriptional reg- 
Figure 8. Complete expression of egl-5::lacZ in muscle cells requires vab-7 activity. (A) Ovals show positions of muscle cell nuclei; red ovals express $v a b-7$ or egl-5. Only one side is shown; staining is equivalent on the other side so that 24 cells express vab-7 and 12 cells express egl-5. All of the egl-5-expressing muscle cells also express vab-7. Dorsal, up; anterior, left. (B) Number of muscle cells that express egl-5::lacZ in wild-type and vab-7 mutant comma to 1.5 -fold stage embryos. $(C, D)$ Merged fluorescence pictures of embryos stained with mAb NE2/4C6.3 to detect muscle cell outlines (green false color) and anti- $\beta$-galactosidase to detect egl-5::lacZ expression (red false color). $(C)$ Wild type; $(D)$ vab-7 mutant. Arrows point to muscle cell nuclei that were counted as positive for egl-5::lacZ expression. In $C 12$ cells were positive; in $D 9$ cells were positive. In $D$, the red channel was made very bright to make the weak muscle staining visible; compare the intensity of nonmuscle staining in $C$ and $D .(E)$ egl5(n945) embryo stained with mAb NE2/4C6.3 to detect muscle cells. Overall organization is normal; cf. $C$ and Fig. 6A,B.
A

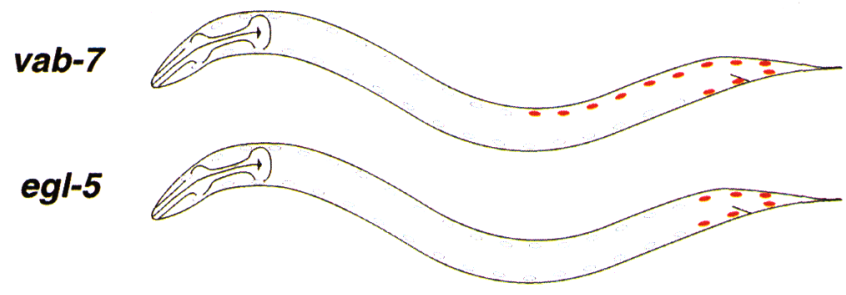

B egl-5::lacZ muscle expression
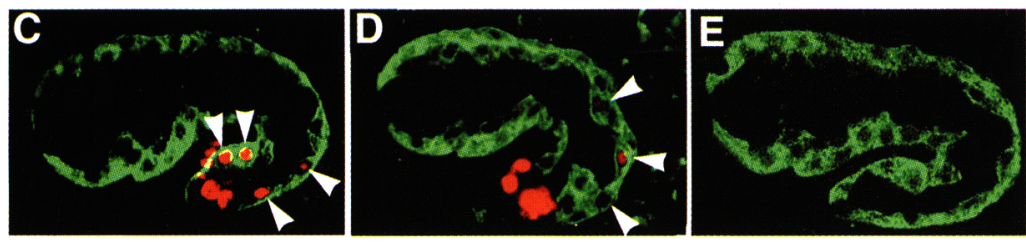

ulators. Most is known about Drosophila eve, the founding member of the gene family. However, its early segmental expression pattern (Macdonald et al. 1986; Frasch et al. 1987) is very different from that of most other animals, and its early function in segmentation (Lawrence et al. 1987) is apparently acquired (Patel et al. 1992).

In all other animals where eve expression patterns have been studied, early posterior mesodermal land usually ectodermal) expression is seen. This includes Xenopus (Xhox-3; Ruiz i Altaba and Melton 1989a), zebrafish (eve1; Joly et al. 1993), mouse (evx1; Bastian and Gruss 1990; Dush and Martin 1992; evx2 is expressed in the posterior at a later time, in a manner similar to that of Hoxd-13; Dollé et al. 1994), and grasshopper levenskipped; Patel et al. 1992). In Xenopus and zebrafish, studies have shown that ectopic eve expression leads to the loss of anterior structures, suggesting a possible patterning function, but the role of the gene in normal development was not determined (Ruiz i Altaba and Melton 1989b; Barro et al. 1994, 1995). Mouse evx1 mutants die at the early postimplantation stage, before the time when expression is found in the posterior mesoderm (Spyropoulos and Capecchi 1994), therefore the role of the posterior eve expression could not be determined. Because strong loss of function vab-7 mutants are viable, its functions can be assayed at all stages in development. The conservation of sequence and posterior expression pattern between $v a b-7$ and eve genes in other animals, including vertebrates, argues that these eve genes all have similar functions. Therefore, it is likely that most eve genes, like vab-7, are involved in posterior mesodermal and ectodermal patterning.

vab-7 and $d / v$ muscle patterning

Loss of $v a b-7$ activity results in the abnormally close association between dorsal and ventral muscles, resulting in disorganized muscle rows and the misplacement of muscles along the $\mathrm{d} / \mathrm{v}$ axis. Is this phenotype due to a transformation of one muscle type to another? As there are no markers to distinguish different body muscles from one another, it is not clear what kind of transformations have taken place. However, the expression pattern of vab-7 can provide some clues. There is a dorsal bias in vab-7 expression, with expression seen in the posterior-most nine muscles of the dorsal muscle rows, but only in the posterior-most three muscles of ventral rows. This bias suggests that vab-7 may be most important for the dorsal muscle fate. In vab-7 mutants, dorsal and ventral muscles appear to have a strong affinity for each other and form unusual attachments, suggesting that they might not recognize each other as different. Therefore, one possibility is that dorsal muscles have taken on ventral fates. Because $v a b-7$ is expressed in some ventral muscles as well as dorsal ones, it could also be that the time or level of $v a b-7$ protein expression determines different fates along the $\mathrm{d} / \mathrm{v}$ axis. Finally, it is likely that other genes act in concert with vab-7 for patterning. Identification of interacting genes and detailed studies of the requirement for $v a b-7$ in different muscles will help to explain the role of $v a b-7$ in $\mathrm{d} / \mathrm{v}$ muscle patterning.

A $\mathrm{d} / \mathrm{v}$ bias in posterior mesoderm expression is a general feature of eve genes. In vertebrates [e.g., mouse evx1 (Bastian and Gruss 1990; Dush and Martin 1992) and zebrafish eve1 (Joly et al. 1993)], expression is concentrated on the ventral side, whereas in Drosophila mesoderm (Frasch et al. 1987; Bodmer 1993) and in C. elegans (this study), expression is greater dorsally. Recent studies have supported the view that the ventral side of vertebrates corresponds to the dorsal side of invertebrates 
(Holley et al. 1995); the different $\mathrm{d} / \mathrm{v}$ biases in eve expression are consistent with this idea.

\section{a/p axial patterning by vab-7 and interaction with} the HOM-C

The most distinctive defects in $v a b-7$ mutants are in $\mathrm{d} / \mathrm{v}$ muscle patterning. However, two phenotypes indicate that $v a b-7$ is also important for a/p patterning. First, in vab-7 mutants two dorsal posterior hypodermal cells have fates similar to those of more anterior hypodermal cells. Second, some dorsal posterior muscles are disordered along the $\mathrm{a} / \mathrm{p}$ axis. In both of these cases, cells undergo abnormal migrations, with the hypodermal cells moving a significant distance anteriorly. The loss of $v a b-7$ activity could result in the transformation to anterior cell fates or may cause cells to have confused instructions that result in aberrant anterior positions.

Although little is known in C. elegans about external positional cues that might guide cells along the a/p axis, it is clear that genes in the HOM-C help give cells appropriate fates (for review, see Salser and Kenyon 1994). These homeotic genes are homologous to related genes in probably all animals, and are most often arranged on the chromosome in the order in which they act along the $\mathrm{a} / \mathrm{p}$ axis (for review, see McGinnis and Krumlauf 1992; Kenyon 1994). In mice and humans, eve genes are physically linked to the "posterior" ends of two homeotic clusters (Faiella et al. 1991; D'Esposito et al. 1991; Dush and Martin 1992; Bastian et al. 1992), and it has been argued that this is the ancestral arrangement (Dolle et al. 1994). This finding, coupled with their expression overlapping and posterior to that of homeotic genes suggests that eve genes might be involved in a/p patterning, possibly acting in concert with the HOM-C. vab-7 is not tightly linked to the C. elegans HOM-C lalthough it is on the same chromosome (III)], but like vertebrate eve genes, its expression is posterior to and overlaps with that of the HOM-C genes. Here, I showed that the most posterior C. elegans HOM-C gene egl-5 requires vab-7 activity for complete expression in muscle cells. This interaction with the HOM-C lends support to the idea that eve genes in general may function as a posterior part of this global a/p patterning system. Loss of egl-5 activity cannot account for the $\mathrm{d} / \mathrm{v}$ muscle patterning defects in vab-7 mutants, as muscle rows in egl-5 mutants are well separated. However, it is possible that the a/p muscle patterning defects in $v a b-7$ mutants are attributable to loss of egl-5 expression; experiments are underway to test this idea.

\section{Zygotic embryonic patterning in C. elegans}

The identification and study of numerous maternal gene products in C. elegans has led to an increasingly detailed view of early patterning events (for review, see Wood and Edgar 1994; Bowerman 1995). How zygotic patterning is initiated in the embryo is largely unknown. It is assumed that the HOM-C genes will be important for embryonic $\mathrm{a} / \mathrm{p}$ patterning, as they begin to be expressed in mid- embryogenesis (Cowing and Kenyon 1992; Clark et al. 1993; Wang et al. 1993|, but their functions have so far only been investigated postembryonically. With the introduction of the $4 \mathrm{D}$ video microscope, full advantage can be taken of the invariant lineage as a powerful tool for the study of embryonic defects. One challenge will be to understand how maternal products initiate zygotic patterning in C. elegans, and the vab-7 gene will provide a new entry point for such studies. Given the simplicity of C. elegans, further work on vab-7 is likely to lead to the identification of additional genes important for animal patterning.

\section{Materials and methods}

Genetic and phenotypic analyses

Worm culture and genetic analyses were as described (Brenner 1974; Wood 1988). The following mutations were used: wild type (Bristoll N2; LGII: fem-1(hc17ts); LGIII: vab-7(1562), vab-7(ed6), vab-7(ed7), tDf2, unc-32(e189), dpy-18(e499); LGV: muls13 [egl-5::lacZ + rol-6(d)|, cc56 (unc-54::lacZ + sup7) muls3 (mab-5::lac $Z+$ rol-6/d)). Extrachromosomal array: muEx19 $[$ egl-5::lacZ + rol-6(d)].

$v a b-7(e 1562)$ was isolated after ethylmethanesulfonate (ems) mutagenesis by I. Culotti (pers. comm.). vab-7(ed6) and vab$7(e d 7)$ are also ems-induced mutations and were isolated in a noncomplementation screen with deficiency $t D f 2$ (which uncovers $v a b$-7) by $M$. Maduro and D. Pilgrim (pers. comm.).

Percent lethality of vab-7(e1562) was determined for three broods at $25^{\circ} \mathrm{C}$; of 279 total progeny, 38 died $(14 \% ; 31$ died as larvae and 7 as embryos). The phenotype of $v a b-7(e 1562)$ over a deficiency was determined as follows. Females of genotype fem1/hc17ts); vab-7(e1562) dpy-18(e499) raised at $25^{\circ} \mathrm{C}$ were mated to single males obtained from crossing $t D f 2 / u n c-32(e 189) d p y-$ $1810499)$ hermaphrodites with wild-type males. Progeny from crosses yielding no Dpy animals (tDf2 does not remove $d p y-18$ ) were scored as Vab or wild type. Of 531 progeny, 293 were scored as wild-type 185 were $\mathrm{Vab}$ and reached adulthood, and 53 died $(3$ as embryos and 50 as larvae). Assuming the Vab and dead animals were of genotype fem-1(hc17ts)/ + vab-7(e1562) dpy$18(e 499) / t D f 2,22 \%(53 / 238)$ of $v a b-7(e 1562) / t D f 2$ animals died (compared with $14 \%$ of vab-7(e1562) homozygotes above). Scoring was conservative and probably included some Vabs in the wild-type class, which will slightly overestimate the lethality of $v a b-7(e 1562) / t D f 2$. Overall, both the percent lethality and the phenotypes of $v a b-7(e 1562)$ homozygotes are similar to those of $v a b-7(e 1562) / t D f 2$, indicating that $v a b-7(e 1562)$ is a strong loss of function allele. The phenotype of $v a b-7(e d 6)$ over either $v a b$ $7(e 1562)$ or the deficiency $t D f 2$ is stronger than that of $v a b$ 7 (ed6) homozygotes. The phenotype of vab-7(ed7) in trans to $v a b-7(e 1562)$ or $t D f 2$ is only slightly stronger than that of $v a b$ 7led7) homozygotes.

\section{vab-7 cloning and sequencing}

Subclones of cosmid M142 were made as follows. pJA12 is the $20-\mathrm{kb}$ PstI fragment from Ml42 cloned into the PstI site of pBSKS $^{-}$(Stratagene). pIA17 is a $14.1-\mathrm{kb}$ SmaI-Pst fragment from M142 made by digesting pJA12 with SmaI / which cuts once in the polylinker $5^{\prime}$ to $v a b-7$ and once in the M142 sequencel and religating it. pJAll is the $8.3-\mathrm{kb}$ SacI fragment from M142 cloned into the SacI site of pBSKS

For testing DNAs for rescuing activity, a cosmid or plasmid at $10 \mu \mathrm{g} / \mathrm{ml}$ was injected together with $100 \mu \mathrm{g} / \mathrm{ml}$ of marker plas- 
mid pRF4 (containing a rol-6/d) gene that causes a dominant rolling phenotype; Mello et al. 1991) using described procedures (Fire 1986; Mello et al. 1991). For MI42, pJA12, and pIA11, rescue was tested in heritable lines that were generated. The $2 / 2$ lines containing M142 each rescued the posterior defects and uncoordinated phenotype of vab-7(e1562), 5/5 lines containing pJA 12 rescued, and $0 / 3$ lines containing pIA 11 rescued. Plasmid pJA17 was tested only for rescue in the $F_{1}$ progeny of injected hermaphrodites. Of $12 \mathrm{~F}_{1}$ rolling hermaphrodites, 7 were rescued.

One cDNA was identified after screening 1 million phage from an embryonic cDNA library in lambda gtll (made by P. Okkema). This phage grew very poorly, therefore the insert was amplified by PCR and cloned into pBSKS $^{-}$two independent times. The sequence was determined on both strands from one clone, and on one strand from another clone using Sequenase (U.S. Biochemical). Software from the Staden package (Staden 1994) was used for sequence assembly. To identify the positions of introns, the sequence of most of the genomic region corresponding to the cDNA was assembled by alternately sequencing regions of pJAll using vab-7-specific primers and Sequenase (U.S. Biochemical) and then obtaining overlapping sequence reads from YAC Y52D3 from the sequencing consortium (not shown). Recently, unfinished cosmid M142 sequence has become available, and the diagram in Figure $1 B$ showing the M142 genomic organization is based on this sequence. The GENE. FINDER program (P. Green, pers. comm.) was used to predict genes within M142; gray boxes in Figure 1A indicate regions of predicted adjacent genes. GENEFINDER predicted the exons found in the vab-7 cDNA described above, but did not predict any additional exons.

To look for mutations associated with $v a b-7$ alleles, the homeo domain was sequenced from each. $v a b-7$-specific primers were used to PCR amplify each of the two exons containing homeo domain sequence along with some intron sequence from homozygous mutant animals. For each mutant, 10 worms were picked into $50 \mu \mathrm{l}$ of $1 \times$ Promega Taq buffer containing 100 $\mu \mathrm{g} / \mathrm{ml}$ of proteinase $\mathrm{K}$ (Sigma), incubated for $1 \mathrm{hr}$ at $65^{\circ} \mathrm{C}$, then heated to $95^{\circ} \mathrm{C}$ for $15 \mathrm{~min}$ to inactivate the proteinase; $5-10 \mu \mathrm{l}$ of this DNA was used for each PCR reaction. The amplified products were purified using Wizard PCR kit (Promega) and sequenced directly with Sequenase and either a ${ }^{32}$ P-labeled primer or with an unlabeled primer and $\left[{ }^{35} \mathrm{~S}\right] \mathrm{dATP}$. Any changes found were confirmed by sequencing an independent PCR product. One change was found in vab-7(e1562) and one in vab7(ed7) (shown in Fig. 1), but no changes were found in the homeo domain of $v a b-7(e d 6)$.

$v a b-7$ appears to be a single copy gene based on Southern blotting; only vab-7 DNA was detected using the vab-7 homeo box as a probe at high stringency $\left(67^{\circ} \mathrm{C}, 5 \times \mathrm{SSC}\right)$. At low stringency $\left(52^{\circ} \mathrm{C}, 5 \times \mathrm{SSCl}\right.$, many additional bands were visible at differing intensities, probably corresponding to the numerous other homeo domain-containing genes (not shown).

\section{vab-7 expression}

For the Northern blot, $\sim 1 \mu \mathrm{g}$ of poly $(\mathrm{A})^{+}$RNA was used per lane (less for the embryonic and adult lanes). Preparation of poly $\mid \mathrm{A}\}^{+}$RNA, formaldehyde/agarose electrophoresis, and blotting were carried out as described (Rosenquist and Kimble 1988) except that Hybond membrane (Amersham) was used. The $v a b-7$ homeo domain sequence was used as a probe, and the blot was reprobed with act-1-specific DNA /Files et al. 1983; insert from plasmid pT3/T7-18-103, from M. Krause, National Institutes of Health, Bethesda, MD|. In situ hybridization was as in Seydoux and Fire (1994) also with a vab-7 homeo domain probe.
The vab-7::lacZ reporter gene contains DNA from the upstream $P_{s t}$ s site in pJA 12 to a $X$ hol site in the second exon of the cDNA (a total of $13.8 \mathrm{~kb}$ ), fused in-frame to the lac $Z$-coding scquence. This was made as follows: plA12 was digested with Xhol, filled in with Klenow, and digested with PstI. The insert was ligated to pPD16.43 (Fire et al. 1990) that had been digested with $X b a I$, filled in using Klenow, and then digested with PstI. This plasmid, designated pJA17, was injected into wild-type hermaphrodites at $50 \mu \mathrm{g} / \mathrm{ml}$ together with pRF4 at $100 \mu \mathrm{g} / \mathrm{ml}$ (as in Fire 1986; Mello et al. 1991) and three heritable lines containing extrachromosomal arrays were obtained. These were assayed for $\beta$-galactosidase activity by staining with $X$-gal (as in Fire et al. 1990; Wang et al. 1993), and all three showed the same pattern of expression. An integrated version, eIs24 (on chromosome II), was isolated after treatment of one of these arrays with $\mathrm{X}$-rays (3500 rads). The pattern of expression of els 24 is the same as that of the extrachromosomal arrays, and it was used for characterization of $v a b-7$ reporter gene expression pattern in Figure 3. els24 does not rescue the vab-7(1562) mutant phenotype.

The cells that express vab-7 RNA by in situ hybridization were identified based on their positions in the embryo. As the early expression from els 24 is indistinguishable from the early in situ pattern, cell identification was confirmed in els $24 \mathrm{em}$ bryos as follows. eIs 24 embryos stuck to polylysine-coated coverslips were mounted in a mixture of fixative and staining solution $150 \mathrm{mM} \mathrm{NaPi}(\mathrm{pH} 7.5), 2 \mathrm{~mm} \mathrm{MgCl}_{2}, 5 \mathrm{~mm} \mathrm{KFe} / 5 \mathrm{~mm} \mathrm{KFo}$, $1 \mu \mathrm{g} / \mathrm{ml}$ of DAPI, $0.004 \%$ SDS, $5 \%$ sucrose, $0.125 \% \mathrm{X}$-gal, $0.7 \%$ glutyraldehyde; G. Seydoux, pers. comm.) on $3 \%$ agar pads also containing this solution. Development was recorded up to the 150-cell stage using the four-dimensional microscope. The eggshell was then permeabilized using a laser to simultaneously fix the embryo and allow detection of $\beta$-galactosidase activity. After incubation overnight at room temperature, the positions of positive cells were recorded, and these were identified unambiguously based on their lineage, which was determined from the earlier recording. In 150-cell stage embryos, both daughters of four cells (a total of 8 ) stained; Caap, Capp, Cpap, Cppp. Later staining cells in els 24 were identified by double staining with markers. For muscle, eIs 24 was double stained with mAb NE8/ 4 C6.2 (Goh and Bogaert 1991 ) and anti- $\beta$-galactosidase (Cappel); for hypodermal cells, double staining was with anti-LIN-26 polyclonal rabbit serum (which stains all epidermal cells; $M$. Labouesse, pers. comm.) and anti- $\beta$-galactosidase (Promega). The cells positive with two antibodies were identified in comma to twofold embryos based on their positions (based on Sulston et al. 19831.

\section{Lineage analyses}

Embryonic lineages were followed using a four-dimensional video recording system (Hird and White 1993). Recordings usually began at the 4-to 12-cell stage and ended as the embryo began to move (after most cell divisions are complete); 20-25 focal planes were recorded every $30 \mathrm{sec}$. For analysis, an embryo-shaped grid printed on a transparency was made containing 10 rows and 10 columns, and this was pasted to the screen while recordings were played. The position on the grid, the time in the recording, and the focal plane were noted for all cell divisions within the $C$ lineage plus most other muscle lineages and many other posterior cells in four vab-7(e1562) embryos. For Figure $7 \mathrm{~B}$, muscle cell positions shown were determined at the bean stage. Muscle cell positions in the other three embryos were similarly defective, although positions varied from animal to animal; data for these are available upon request. 


\section{Reporter gene and muscle marker assays}

Antibody staining of embryos was as in Albertson (1984). $\beta$-Galactosidase activity from reporter genes was detected either using X-gal (as in Fire et al. 1990 for adults or Wang et al. 1993 for embryos) or using an anti- $\beta$-galactosidase antibody (Cappel or Promega). Overall muscle organization was assayed in adults with a body wall myosin reporter gene called PD56(cc56) (Okkema et al. 1993; an unc-54::lacZ fusion genel and in embryos by staining with mAb NE8/4C6.3, which stains the outlines of body wall muscle cells (Goh and Bogaert 1991).

mab-5 expression was assayed using muIs 3 , a mab-5::lacZ fusion gene (Cowing and Kenyon 1992). Embryos were stained with X-gal and total stained cells counted. An average of 13 cells stained in both wild-type $(n=18)$ and vab-7(e1562) mutant $(n=15)$ comma stage embryos. The total number of cells expressing egl-5::1acZ was counted using muEx19 (Wang et al. 1993), an extrachromosomal array that is lost mitotically, resulting in variable staining. At the comma stage, an average of 19 cells (range 9-31, $n=28$ ) expressed egl-5::lacZ in wild type versus 13 cells (range $3-21, n=26$ ) in vab-7(e1562) mutants. At the threefold stage, an average of 26 cells (range 15-32, $n=33$ | expressed egl-5::1acZ in wild type versus 18 cells /range 13-27, $n=39$ ) in vab-7(e1562) mutants. muIs13 (an integrated version of $m u E x 19 ;$ S. Salser and C. Kenyon, pers. comm.) was used to count the number of muscle cells that express egl-5::lacZ. Embryos were costained with $\mathrm{mAb} N E 8 / 4 \mathrm{C} 6.3$ and rabbit anti- $\beta$ galactosidase polyclonal serum (Cappel), and the number of cells staining with both were counted in wild type and $v a b$. 7(e1562) mutant comma to 1.5 -fold stage embryos. Nonmuscle staining of egl-5::lac $Z$ was of similar intensity in wild-type and vab-7 mutant embryos, but muscle cell staining was often very weak in vab-7 mutants. To aid in identifying these weakly stained muscle cells, a confocal microscope was used; this was unnecessary for wild-type embryos. egl-5::1acZ-expressing cells are missing from all four muscle rows (not shown).

\section{Acknowledgments}

I thank the following people for sending me reagents, strains, and protocols: A. Coulson for cosmids, A. Fire for PD56, M. Krause for an act-1 plasmid, M. Labouesse for anti-LIN-26 antibody, M. Maduro and D. Pilgrim for vab-7 alleles, P. Okkema for cDNA libraries, S. Salser and C. Kenyon for HOM-C::lacZ strains, and G. Seydoux for in situ and lacZ staining protocols. $I$ am also grateful to $M$. Berks and the rest of the $C$. elegans sequencing consortium for Y52D3 and M142 sequence, and to R. Durbin for help with genefinding. R. Durbin, M. Freeman, J. Hodgkin, P. Lawrence, and J-P. Vincent gave me helpful comments on the manuscript. Finally, I thank the Cell Biology division for laboratory space and colleagues for discussions.

\section{Note added in proof}

The EMBL accession number for the $v a b-7$ cDNA sequence is X96636.

\section{References}

Albertson, D.G. 1984. Formation of the first cleavage spindle in nematode embryos. Dev. Biol. 101: 61-72.

Barro, O., C. Joly, H. Condamine, and H. Boulekbache. 1994. Widespread expression of the Xenopus homeobox gene $X h o x 3$ in zebrafish eggs causes a disruption of the anteriorposterior axis. Int. J. Dev. Biol. 38: 613-622.

Barro, O., S. Vriz, J.S. Joly, C. Joly, H. Condamine, and H.
Boulkebache. 1995. Widespread expression of the eve1 gene in zebrafish embryos affects the anterior-posterior axis pattern. Dev. Genet. 17: 117-128.

Bastian, H. and P. Gruss. 1990. A murine even-skipped homologue, $E_{V X} 1$, is expressed during early embryogenesis and neurogenesis in a biphasic manner. EMBO /. 9: 1839-1852.

Bastian, H., P. Gruss, D. Duboule, and J.C. Izpisuabelmonte. 1992. The murine even-skipped-like gene evx-2 is closely linked to the Hox-4 complex, but is transcribed in the opposite direction. Mamm. Genome 3: 241-243.

Billeter, M., Y.Q. Qian, G. Otting, M. Muller, W. Gehring, and K. Wuthrich. 1993. Determination of the NMR solution structure of an Antennapedia homeodomain-DNA complex. l. Mol. Biol. 234: 1084-1094.

Bodmer, R. 1993. The gene tinman is required for specification of the heart and visceral muscles in Drosophila. Development 118: 719-729.

Bowerman, B. 1995. Determinants of blastomere identity in the early C. elegans embryo. BioEssays 17: 405-414.

Brenner, S. 1974. The genetics of Caenorhabditis elegans. Genetics $77: 71-94$.

Clark, S.G., A.D. Chisholm, and H.R. Horvitz. 1993. Control of cell fates in the central body region of $C$. elegans by the homeobox gene lin-39. Cell 74: 43-55.

Costa, M., M. Weir, A. Coulson, J. Sulston, and C. Kenyon. 1988. Posterior pattern formation in C. elegans involves position-specific expression of a gene containing a homeobox. Cell 55: 747-756.

Cowing, D.W. and C. Kenyon. 1992. Expression of the homeotic gene mab-5 during Caenorhabditis elegans embryogenesis. Development 116: 481-490.

D'Esposito, M., F. Morelli, D. Acampora, E. Migliaccio, A. Simeone, and E. Boncinelli. 1991. EVX2, a human homeobox gene homologous to the even-skipped segmentation gene, is localized at the $5^{\prime}$ end of HOX4 locus on chromosome 2 . Genomics 10: 43-50.

Dollé, P., V. Fraulob, and D. Duboule. 1994. Developmental expression of the mouse $E_{V X}-2$ gene: Relationship with the evolution of the HOM/Hox complex. (Suppl.) Development: $143-153$

Dush, M.K. and G.R. Martin. 1992. Analysis of mouse Evx genes: $E V X X-1$ displays graded expression in the primitive streak. Dev. Biol. 151: 273-287.

Faiclla, A., M. D'Esposito, M. Rambaldi, D. Acampora, S. Balsofiore, A. Stornaiuolo, A. Mallamaci, E. Migliaccio, M. Gulisano, A. Simeone, et al. 1991. Isolation and mapping of EVX1, a human homeobox gene homologous to evenskipped, localized at the $5^{\prime}$ end of HOX1 locus on chromosome 7. Nucleic Acids Res. 19: 6541-6545.

Files, J.G., S. Carr, and D. Hirsh. 1983. Actin gene family of Caenorhabditis elegans. I. Mol. Biol. 164: 355-375.

Fire, A. 1986. Integrative transformation of C. elegans. EMBO J. 5: 2673-2680.

Fire, A., H.S. White, and D. Dixon. 1990. A modular set of lac Z fusion vectors for studying gene expression in Caenorhab. ditis elegans. Gene 93: 189-198.

Frasch, M., T. Hoey, R. Christine, H. Doyle, and M. Levine. 1987. Characterization and localization of the even-skipped protein of Drosophila. EMBO I. 6: 749-759.

Frasch, M., R. Warrior, J. Tugwood, and M. Levine. 1988. Molecular analysis of even-skipped mutants in Drosophila development. Genes \& Dev. 2: 824-1838.

Gehring, W.J., Y.Q. Qian, M. Billeter, K. Furukubotokunaga, A.F. Schier, D. Resendezperez, M. Affolter, G. Otting, and K. Wuthrich. 1994. Homeodomain-DNA recognition. Cell 78: $211-223$. 
Goh, P.-Y. and T. Bogaert. 1991. Positioning and maintenance of embryonic body wall muscle attachments in C. elegans requires the mup-1 gene. Development 111: 667-681.

Hird, S.N. and J.G. White. 1993. Cortical and cytoplasmic flow polarity in early embryonic cells of Caenorhabditis elegans. J. Cell Biol. 121: 1343-1355.

Holley, S.A., P.D. Jackson, Y. Sasai, B. Lu, E.M. Derobertis, F.M. Hoffmann, and E.L. Ferguson. 1995. A conserved system for dorsal-ventral patterning in insects and vertebrates involv. ing sog and chordin. Nature 376: 249-253.

Joly, J.-S., C. Joly, S. Schulte-Merker, H. Boulekbache, and H. Condamine. 1993. The ventral and posterior expression of the zebrafish homeobox gene eve1 is perturbed in dorsalized and mutant embryos. Development 119: 1261-1275.

Kenyon, C. 1994. If birds can fly, why can't we? Homeotic genes and evolution. Cell 78: 175-180.

Lawrence, P.A., P. Johnston, P. Macdonald, and G. Struhl. 1987. Borders of parasegments in Drosophila embryos are delimited by the fushi tarazu and even-skipped genes. Nature 328: 440-442.

Macdonald, P., P.W. Ingham, and G. Struhl. 1986. Isolation, structure, and expression of even-skipped: A second pairrule gene of Drosophila containing a homoebox. Cell 47: 721-734.

McGinnis, W. and R. Krumlauf. 1992. Homeobox genes and axial patterning. Cell 68: 283-302.

Mello, C.C., J.M. Kramer, D. Stinchcomb, and V. Ambros. 1991. Efficient gene transfer in C. elegans: Extrachromosomal maintenance and integration of transforming sequences. EMBO /. 10: 3959-3970.

Miles, A and D.J. Miller. 1992. Genomes of diploblastic organisms contain homeoboxes: Sequence of eveC, an evenskipped homologue from the cnidarian Acropora formosa. Proc. R. Soc. Lond. Biol. 248: 159-161.

Okkema, P.G., S.W. Harrison, V. Plunger, A. Arvans, and A. Fire. 1993. Sequence requirements for myosin gene expression and regulation in Caenorhabditis elegans. Genetics 135: 385-404.

Patel, N.H., E.E. Ball, and C.S. Goodman. 1992. Changing role of even-skipped during the evolution of insect pattern formation. Nature 357: 339-342.

Rosenquist, T.A. and J. Kimble. 1988. Molecular cloning and transcript analysis of fem-3, a sex-determination gene in $C$. elegans. Genes \& Dev. 2: 606-616.

Ruiz i Altaba, A. and D.A. Melton. 1989a. Bimodal and graded expression of the Xenopus homeobox gene Xhox 3 during embryonic development. Development 106: 173-183.

- 1989b. Involvement of the Xenopus homeobox gene Xhox3 in pattern formation along the anterior-posterior axis. Cell 57: 317-326.

Salser, S.J. and C. Kenyon. 1994. Patterning C. elegans: Homeotic cluster genes, cell fates and cell migrations. Trends Genet. 10: 159-164.

Seydoux, G. and A. Fire. 1994. Soma-germline asymmetry in the distributions of embryonic RNAs in Caenorhabditis ele. gans. Development 120: 2823-2834.

Slack, J.M.W. 1991. From egg to embryo. Cambridge University Press, Cambridge, UK.

Spyropoulos, D.D. and M.R. Capecchi. 1994. Targeted disruption of the even-skipped gene, evx1, causes early postimplantation lethality of the mouse conceptus. Genes \& Dev. 8: 1949-1961.

Staden, R. 1994. Staden. Methods Mol. Biol. 25: 9-170.

Sulston, J.E., E. Schierenberg, J.G. White, and J.N. Thomson. 1983. The embryonic cell lineage of the nematode Caenorhabditis elegans. Dev. Biol. 100: 64-119.
Tomlinson, A., B.E. Kimmel, and G.M. Rugin. 1988. rough, a Drosophila homeobox gene required in photoreceptors R2 and $\mathrm{R} 5$ for inductive interactions in the developing eye. Cell 55: $771-784$.

Wang, B.B., I.M. Muller, J. Austin, N.T. Robinson, A. Chisholm, and C. Kenyon. 1993. A homeotic gene cluster patterns the anteroposterior body axis of C. elegans. Cell 74: 29-42.

Wood, W.B. 1988. The Nematode Caenorhabditis elegans. Cold Spring Harbor Laboratory, Cold Spring Harbor, NY.

Wood, W.B. and L.G. Edgar. 1994. Patterning in the C. elegans embryo. Trends Genet. 10: 49-54. 


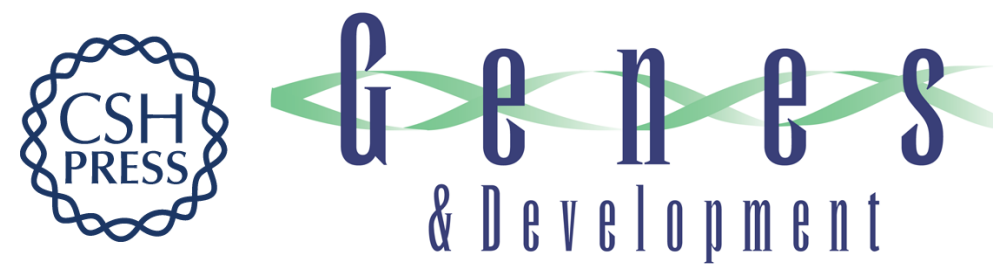

\section{Posterior patterning by the Caenorhabditis elegans even-skipped homolog vab-7.}

$J$ Ahringer

Genes Dev. 1996, 10:

Access the most recent version at doi:10.1101/gad.10.9.1120

References This article cites 44 articles, 11 of which can be accessed free at:

http://genesdev.cshlp.org/content/10/9/1120.full.html\#ref-list-1

License

Email Alerting

Service

Receive free email alerts when new articles cite this article - sign up in the box at the top right corner of the article or click here.

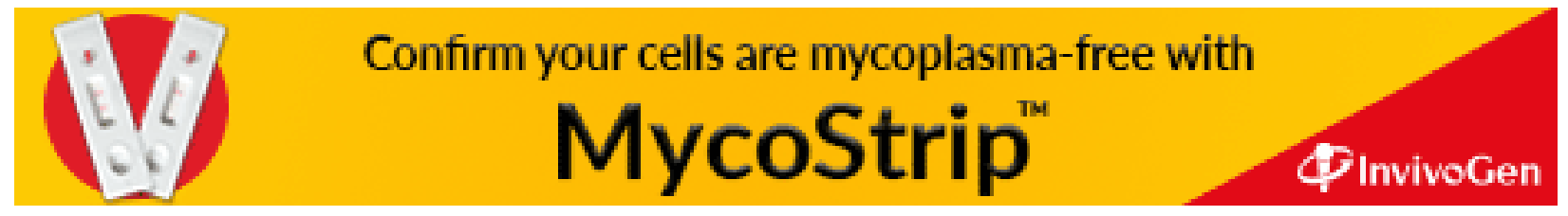

